\title{
Flexibility In Manufacturing And Activity Based Costing: Modelling The Interrelationships
}

George Venieris, Athens University of Economics and Business, Greece Sandra Cohen, Athens University of Economics and Business, Greece

\begin{abstract}
Theory claims that $A B C$ is most suitable for companies employing flexibility in manufacturing, as it is a vehicle for more accurately depicting cost causation when the level of overheads increases. Furthermore, the benefits of flexibility in production can only be visible when sophisticated cost accounting systems, such as $A B C$, are implemented. However, previous empirical studies have shown that this is not always the case. In this paper we develop a model, which proposes whether $A B C$ implementation should be recommended by combining several attributes that, according to theory and previous empirical findings, characterize sophisticated cost accounting systems and flexibility in production. This model can be used to assist companies to assess the suitability and applicability of $A B C$, under their own specific business conditions regarding production flexibility. In order to evaluate the reliability of the model we have empirically tested it to a sample of leading Greek manufacturing firms. The model developed succeeded in identifying, at a statistically significant level, the perceptions of managers about the suitability of $A B C$ for their companies. It also revealed that production flexibility is a significant factor driving companies towards $A B C$ adoption.
\end{abstract}

\section{INTRODUCTION}

C al., 2000).

A plethora of parameters has been tested in the literature in order to explain this paradox. These parameters include strategic posture and organizational structure (Gosselin, 1997), the role of demand factors (Bjørnenak 1997), as well as factors that influence the diffusion of innovations, considering $\mathrm{ABC}$ as a form of administrative innovation (Malmi, 1999).

Empirical evidence also shows that behavioral and organizational variables influence successful $\mathrm{ABC}$ implementation (Shields, 1995; Foster and Swenson, 1997; McGowan and Klammer, 1997; Friedman and Lyne, 1999; Anderson and Young, 1999). On the other hand, the seriousness of the investment decision, on financial grounds, has been presented as a drawback for ABC implementation (Cobb et al., 1992; Malmi, 1997).

Another parameter that influences sophisticated cost accounting systems' implementation is manufacturing flexibility. Manufacturing flexibility complicates costing procedures, as accurate overhead allocation becomes a complicated task when configurations and product mix keep changing. However, the research regarding the relationship between flexibility in manufacturing and $\mathrm{ABC}$ suitability is rather limited with a few exceptions (Abernethy and Lillis, 1995; Koltai et al., 2000). This is the focal point of the present paper. 
As we believe that production flexibility plays an important role in $\mathrm{ABC}$ adoption decision, we have developed in this paper a simple and adaptable model that could assist managers to identify whether the adoption of $\mathrm{ABC}$ could be a helpful management tool for them. Thus, the goal of the model is to present the context whithin which $\mathrm{ABC}$ can best assist managers under different levels of production flexibility. The output of the model is based on a combination of several attributes that, according to theory and previous empirical findings, characterize sophisticated cost accounting systems and flexibility in production.

In order to assess the reliability of the model we have applied it to 55 Greek manufacturing firms in order to test whether management's perception about the suitability of $\mathrm{ABC}$ is compatible with what is proposed by the model. The results of this test are very encouraging and as the sample characteristics in terms of production flexibility and cost parameters are comparable to previous samples in other countries, the results may also be applicable elsewhere.

On the basis of the above, the targets of the paper are, first, to provide an easy to apply model that would justify the decision on the adoption of $\mathrm{ABC}$ on the basis of production flexibility, and second, to contribute to the debate why $\mathrm{ABC}$ systems, despite their theoretical advantages, have not yet been overwhelmingly accepted and adopted.

The paper is structured as following: the literature review is presented first followed by the methodology, where the characteristics of the model developed and the research method are presented. The empirical results and the descriptive statistics of the survey along with the empirical results of the model are described next. The final section of the paper contains a discussion on the research findings and the conclusions.

\section{Literature Review}

From the literature review one can infer that despite the strong advocacy in favor of ABC (Cooper, 1988a, 1988b; Cooper and Kaplan, 1991, 1992, 1998; Kaplan, 1992) adoption rates are not overwhelming (Innes et. al., 2000).

Survey evidence suggests that, over the past decade, there has been a global growing awareness of activity based costing, but the overall rate of implementation has been low. The U.K. surveys in the early 1990s reported adoption rates of about 10\% (Innes and Mitchell, 1991; Nicholls, 1992) while more recent research reveals higher adoption rates of around 20\% (Innes and Mitchell, 1995; Innes et. al., 2000, Banerjee and Kane, 1996; Evans and Ashworth,1996).

Evidence from continental Europe suggests a slower rate of adoption of activity based costing techniques with adoption rates less than 10\% (Israelsen et al., 1996; Ask et al., 1996; Lukka and Granlund, 1996; Scherrer, 1996; Barbato et. al., 1996; Saez-Torrecilla et al., 1996).

It has been argued in cost accounting literature that traditional cost accounting systems are obsolete and inefficient to cope with the new environment characterized by modern production technology and intensive competition (Cooper, 1988b; Johnson and Kaplan, 1987). New production technology has been seen as a crucial factor in the change of the cost structure of many companies, i.e., increased participation of indirect cost in comparison to direct cost. $\mathrm{ABC}$ has been proposed as a solution for handling the increased indirect costs (Kaplan, 1983). It follows that $\mathrm{ABC}$ becomes important when there are large indirect costs and that the link between production costs and cost objects is complex.

However, empirical surveys have offered contradicting evidence in respect to this issue. Bjørnenak (1997) found a weak support for the proposition that adopters of $\mathrm{ABC}$ have a different cost structure and higher overheads than non - $\mathrm{ABC}$ adopters. On the other hand, no significant difference between $\mathrm{ABC}$ users and non- $\mathrm{ABC}$ users was indicated by Clarke et al. (1999) and Groot (1999), regarding the percentage of manufacturing overhead to total cost, and overhead costs (either in absolute or relative terms) respectively. 
In recent years manufacturing flexibility has emerged as a key weapon of companies that face competitive pressures. A number of empirical surveys have studied the relationship between manufacturing flexibility and performance (Vokurka and O' Leary-Kelly, 2000; Beach et. al., 2000) while several others have been published discussing concepts and measures of flexibility (Sethi and Sethi, 1990; Gupta and Somers, 1992; Browne et. al., 1984). However, although the research in these fields is intense, researchers use different definitions of manufacturing flexibility. A working definition of flexibility in manufacturing is that it is a multidimensional construction that represents the ability of the manufacturing function to adjust and/or to react to environmental changes without significant sacrifices to firm's performance (D' Souza and Williams, 2000).

In recent years there has been an increasing degree of adoption of computer integrated manufacturing (CIM) technologies such as computer aid manufacturing (CAM), flexible manufacturing systems (FMS) and automated storage and retrieval systems (AS/RS). These technologies aim to the development of flexible manufacturing capabilities that create or sustain a competitive advantage. Companies can choose between a variety of flexibility options in order to enhance their competitive position (Suarez et al., 1995). More specifically, the perceived benefits of FMS have been identified as smaller inventories of work in progress, faster production processes, improved response to customer needs, stable product quality, decreased finished goods inventories and decreased production costs per unit (Avlonitis and Parkinson, 1986).

While in theory a serious change in the production process should be followed by a change in the accounting system, empirical surveys give mixed evidence. Cohen and Paquette (1991) found that controllers persistently considered the existing costing systems to be adequate, even after the introduction of new production techniques. Lukka and Granlund (1996) in a study of 135 Finish companies found that about the half of the respondents considered that the application of new philosophies in operations and advanced manufacturing technologies had affected product costing. However, $39 \%$ of the respondents had not perceived such effects.

On the other hand, Foster and Horngren (1988), on the basis of the results of a field study of 25 U.S. and U.K. companies, reported that the introduction of FMS had been followed by the abandonment of labour costs as direct costs. Some firms, however, had not changed their cost accounting systems at all.

Abdel-Kadar and Duglade (1998) investigated the investment decision making practices of large U.K. manufacturing companies regarding investments in advanced technologies. They concluded that, in order to justify such investments on economic grounds a more sophisticated cost accounting system is required. Chen (1996) shares the same views. Bromwich and Hong (1999) argue that the ability of ABC to measure products' economic costs is influenced by technology characteristics. However, a recent study by Johnston et al. (2002) depicted that the involvement of management accountants to process improvement programmes was limited to about $50 \%$ of the cases analysed.

From the literature review we can conclude that both the adoption rates of $\mathrm{ABC}$ have been moderate and that firms that operate in advanced technological environments that are characterized by manufacturing flexibility, even though they could undoubtedly gain benefits, have not willingly adopted ABC. Moreover, the changes in production towards flexibility have not changed in all cases the perceptions of management accountants regarding the suitability of their less sophisticated cost accounting systems. Nevertheless, the more recent surveys evidence that the majority of manages anticipates the need for changes towards a more sophisticated system due to the manufacturing flexibility parameter. Thus, manufacturing flexibility has eventually driven managers to be dissatisfied from their traditional cost accounting system and acknowledge $\mathrm{ABC}$ benefits.

The model we have developed intends to isolate the flexibility on production from the other potential parameters (discussed in the introduction) that influence $A B C$ adoption and implementation in order to give an answer to the following question: "Given the level of a company's production flexibility is the adoption of a sophisticated cost accounting system recommended?" 


\section{METHODOLOGY}

\section{The Model}

Three steps were followed for the formulation of the decision model: a) selection of attributes, b) weight differentiation of attributes and c) model matrix development. In the following paragraphs each one of the above steps is described in detail.

\section{Selection Of Attributes}

We first defined the attributes regarding cost accounting systems sophistication and production flexibility. An attribute is a characteristic that evaluates either the cost accounting system's sophistication used by a company and/or the degree of its production flexibility. A company may either have an attribute or not. All the attributes are meant to be independent from one another in order to capture different aspects of the two predefined dimensions. More specifically, the attributes of production flexibility correspond to different aspects and definitions of flexibility. It is frequently evidenced that a company may possess one aspect and lack another. The same holds true for the cost characteristics of the firms. The cost characteristics relate to heterogeneous parameters that are not bound to relate. We finally concluded on five attributes for each one of the two dimensions under analysis. The attributes that were selected for the model are based on theory and capture a considerable part of previous research findings. Thus they were considered adequate and applicable for this purpose.

The five attributes regarding cost accounting sophistication $\left(A_{c}\right)$ are the following:

Attribute $A_{c l}$ : Considerable indirect cost contribution to production cost.

The percentage contribution of production cost elements influences the characteristics of the cost accounting system in several ways. Proponents of $\mathrm{ABC}$ have argued that cost distortions arising from traditional overhead allocations are more significant as overhead is a considerable component of production cost (Cooper, 1988b). Thus, a more sophisticated cost accounting system is needed when a company has a relatively high proportion of indirect production costs (Bjørnenak, 1997).

Attribute $A_{c 2}$ : Unsuitability of burden rates used.

One of the main criticisms against traditional cost accounting systems is that they use volume allocation bases that are obsolete within the new environment of modern production technology (Cooper, 1988a). A change to a more sophisticated cost accounting system is needed for a company when it still uses traditional burden rates (direct labour hours or direct labour cost) to allocate indirect costs even though the cost of direct labour is a small percentage of the total production cost. On the other hand, the cost distortions may still exist but they may not be of the same severity when a company uses machine hours to allocate indirect costs that are related to automation under such production conditions.

Attribute $A_{c 3}$ : Existence of significant direct non production costs.

Traditional cost accounting systems have also been criticized for the simplistic way they treat non production costs even thought they have direct relation to products. These non-production direct product costs relate mainly to selling and marketing costs. The allocation process may result to miscalculations of total product cost, if these direct non production costs account for a considerable percentage of total product cost. Thus, a company is more likely to use a more sophisticated cost accounting system when it has a high percentage of selling and marketing expenses that is feasible to be directly linked to specific products. On the contrary, if these expenses relate to the overall marketing and selling policy of the company, i.e. relate to facility sustaining activities, the adoption of a more sophisticated cost accounting system is less needed, as it is likely that it will not improve the application of cost causation principles in respect to these expenses. 
Attribute $A_{c 4}$ : Decision making on the basis of cost data.

In the new environment of intensive competition, managers want to extract, from the cost accounting systems, information relevant for decision making. The need for a sophisticated cost accounting system is also driven by the information requirements of management. If the management wants to have cost information through out the value chain, a more detailed cost accounting system is needed. The non relevancy of cost accounting information is one of the reasons that motivates companies to change their cost accounting systems (Malmi, 1999). A more sophisticated cost accounting system, like $\mathrm{ABC}$, provides information that is relevant for cost reduction and cost management, pricing decisions, product mix decisions, etc. (Innes and Michell, 1995; Innes et al., 2000). However, when a company uses accounting information only for stock evaluation and budget preparation is more likely not to need a more sophisticated cost accounting system, as this type of costing information can easily be obtained from a traditional cost accounting system. Furthermore, stock evaluation and budget preparation are not significant in assessing the success of an ABC system (Innes et. al., 2000).

Attribute $A_{c 5}$ : Significant contribution of non production costs to total costs.

A company that its cost structure is characterized by a high percentage of "below the line expenses", i.e. selling and marketing, administration and research and development expenses, is more likely to need a more sophisticated cost accounting system. These overheads need a closer monitoring as occasionally hide the existence of non-value added activities. Within an ABC context these costs can be assigned to activities of different levels (i.e. product line level activities, business level activities, customer related activities). This procedure not only permits an accurate product cost calculation (Cooper, 1988a) but also allows the undertaking of a customer profitability analysis. Traditional cost accounting systems have been seriously criticized because they usually cause total product cost distortions due to the arbitrary allocation of general overhead (i.e. contribution to sales revenue, production cost, etc.). When these overheads refer to a low percentage of total costs, the degree of possible distortions is reduced and the adoption of a more sophisticated cost accounting system is less needed.

The five attributes regarding production flexibility $\left(A_{f}\right)$ are presented below. Our perception about manufacturing flexibility is mainly based on the work of Gerwin (1993), Sethi and Sethi, (1990) and Gupta and Somers (1996), who have indicated various aspects of manufacturing flexibility.

Attribute $A_{f l}$ : High number of different products produced through the same facilities.

The number of different products produced through the same manufacturing equipment facilities is an indication of the production system's flexibility. This attribute is usually called mix or variety flexibility (Gerwin, 1993; D' Souza and Williams, 2000). Thus, the higher the number of different products produced through the same manufacturing facilities the higher the flexibility of the system.

Attribute $A_{f 2}$ : Lack of significant manufacturing alterations for product modifications.

A characteristic of flexible manufacturing systems is that the technical characteristics of the products can be easily altered without causing or by causing minor modifications to the manufacturing equipment used. Also, new products can be easily added to a production line. This attribute is usually called modification flexibility (Gerwin, 1993). A production system possesses this attribute when alterations in the technical characteristics of the products do not require significant changes in existing equipment.

Attribute $A_{f 3}$ : Frequent set-ups performed in short response times.

In a flexible production process the number and the frequency of set-ups is increased in comparison to traditional production processes. Furthermore, parameters that characterize flexibility are also the short response time and the low cost in executing the change orders. This attribute is usually called flexibility responsiveness (Gupta and Goyal, 1989; Sethi and Sethi, 1990) or process flexibility (D'Souza and Williams, 2000). Thus, a production system possesses this attribute of flexibility when it includes frequent set-ups that correspond to short 
response times. On the other hand, a production system that has only a few set-ups (mass production) and the process for their execution is time consuming does not possess this attribute.

Attribute $A_{f 4}$ : Batch size determination based on orders.

In a flexible production environment a company is able to economically adjust the batch size of its production to demand factors. The capability of producing products in small batches, the size of which depends on customers' requirements, is a characteristic of flexibility in production. This attribute is usually called volume flexibility (Gerwin, 1993; D'Souza and Williams, 2000). However, when products are only produced in sizeable predetermined batches due to significant set-up costs and technical characteristics of the manufacturing equipment, the production process of a company is less flexible and the company lacks this attribute.

Attribute $A_{f 5}$ : High degree of automation in material handling.

A production system that is characterized by materials' handling flexibility has the ability to effectively deliver them to the appropriate stages of the manufacturing process (Gerwin, 1993; Sathi and Sathi, 1990). More specifically, the movement of raw materials, work-in-process and finished goods to the different production phases is done via automated means (i.e. material handling systems-MHS). The extensive human involvement in the circulation of raw materials and goods in different stages of completion decrease the degree of the production system flexibility. Under such conditions a company does not possess this particular attribute.

\section{Weights Of Attributes}

Following the selection of the attributes, we assumed that all attributes are of equal importance within the model. This means that the cost accounting attributes have all the same weights, and are not different from those regarding production flexibility attributes. So, the equivalence hypothesis holds either among the attributes of each category or between categories. In real world, the importance of a characteristic may differ considerably among companies. However, instead of arbitrarily assigning different weights to various attributes, we opted for the safer approach assuming that all attributes are of equal importance.

\section{Development Of Model Matrix}

Our last methodological step was to plot the attributes to a matrix. For this reason a matrix was invented that has four quadrants. The horizontal axis corresponds to the cost accounting sophistication variable and the vertical axis corresponds to the production flexibility variable. A high or a low concern for each variable places the companies into a quadrant (Figure 1).

Thus, the relationships between the variable attributes can be depicted by the four quadrants of the matrix. Each quadrant proposes $\mathrm{ABC}$ or no $\mathrm{ABC}$ implementation based on different reasoning.

The meaning of each quadrant is the following:

Quadrant 1: A company that is positioned in quadrant 1 is not expected to need an $\mathrm{ABC}$ system. The reason is that this company has both low production flexibility and its cost structure can be still adequately depicted by a traditional cost accounting system.

Quadrant 2: A company that lays in quadrant 2 is expected to need an $\mathrm{ABC}$ system. The reason is that even though the cost structure of this company is rather similar to that of a company placed in quadrant 1 , this company is characterized by flexibility in production. Thus, the flexible production conditions create the need for sophisticated cost treatment in order accurate measurements be achieved and accurate cost information be produced.

Quadrant 3: An ABC system is expected to be suitable also for companies that lay in quadrant 3 even though these companies are characterized by low flexibility. The existence of a cost accounting system that is not adequate to 
present accurate cost accounting data and data relevant for decision making are the underlying factors that make $\mathrm{ABC}$ adoption a suitable prospect.

Quadrant 4: An ABC system is expected to be suitable for a company that is positioned in the 4th quadrant. This company has both increased automation and flexibility, that have eventually influenced its cost structure, in relation to production and non-production costs, and, furthermore, its management wants to rely on detailed and accurate accounting data `decision making.

Figure 1: The Model Matrix

\begin{tabular}{|c|c|c|}
\hline Degree of & $\begin{aligned} A_{f j} & =\text { High } \\
A_{c j} & =\text { Low } \\
\text { Quadrant 2 } & \end{aligned}$ & $\begin{aligned} A_{f j} & =\text { High } \\
A_{c j} & =\text { High } \\
\text { Quadrant } 4 & \end{aligned}$ \\
\hline $\begin{array}{l}\text { Degree of } \\
\text { Flexibility } \\
\text { in production }\end{array}$ & $\begin{aligned} A_{f j} & =\text { Low } \\
A_{c j} & =\text { Low } \\
\text { Quadrant 1 } & \end{aligned}$ & $\begin{aligned} A_{f j} & =\text { Low } \\
A_{c j} & =\text { High } \\
\text { Quadrant 3 } & \end{aligned}$ \\
\hline Low & & High \\
\hline
\end{tabular}

In summary, $\mathrm{ABC}$ would be more suitable for a company when it is located in quadrants 2,3 or 4 . The results of the model regarding the values of attributes are presented next and the analytical attributes' scoring calculations can be found in the Appendix.

\section{Research Design And Data Collection}

The theoretical model that was described in the previous paragraphs was eventually empirically tested by using data referring to Greek manufacturing companies. The scope of this empirical testing was to control the implied hypotheses that were developed within the context of the model. Moreover, it would permit the assessment of the degree at which the results of the model regarding $\mathrm{ABC}$ suitability were compatible with the perceptions of management. This test would verify, upon actual data, whether the model could be used as a guide by a decision maker towards assessing the suitability of $\mathrm{ABC}$ for his/her company, before embarking in developing and implementing a capital spending project like $\mathrm{ABC}$.

A postal questionnaire was used in order to collect primary data. Pilot interviews, with financial managers of two manufacturing firms were conducted as well as the opinion of an academic specialized in advanced manufacturing processes was asked, in order to ensure that the final version of the questionnaire was of manageable length and free of misunderstandings.

The questionnaire had two parts. The first part contained questions regarding management accounting information and was addressed to the financial manager of the company. The second part contained questions regarding the production process and was addressed to the production manager.

A sample of 174 Greek manufacturing companies was chosen out of the 500 largest Greek manufacturing firms in 1998 with the target of having a rather equal representation of the main industrial sectors in Greece. The grouping of the 500 largest Greek manufacturing firms was based on various criteria, such as the number of employees, the turnover and the value of fixed assets, deriving from publicly and was derived by publicly available data. The reason why we did not choose a random sample of firms is because there is considerable evidence that size influences adoption rates of activity based costing techniques (Innes et. al., 2000; Bjornenak, 1997; Drury and Tales, 1994). Furthermore, similar surveys in U.K have concentrated to large companies (Innes and Michell, 1995; Innes et al., 2000). Also, as $\mathrm{ABC}$ projects are resource consuming and require sufficient personnel, computing facilities and 
time (Cobb et. al., 1993; Anderson, 1995) their realization is expected to be more frequent among the largest manufacturing companies, which can afford the relevant high costs (Innes and Michell, 1995; Shields, 1995).

The questionnaires were mailed by the end of May 1999 and were personally addressed to the 174 financial directors. A follow up telephone call was made or fax was sent to non-respondents at the end of June 1999 and by the middle of July 199955 responses were received. The response rate was $31.6 \%$.

\section{Survey Results And Descriptive Statistics}

Demographic and industry features of the respondents (regarding the first part of the questionnaire) are summarized in Table I.

An important aspect of this study relates to the cost structure of the companies analyzed, since cost structure is regarded as an important factor affecting the appropriateness of a sophisticated cost accounting system. Furthermore, cost structure characteristics are necessary in order to give values to attributes $A_{c l}, A_{c 2}$ and $A_{c 5}$. Also the percentage of selling expenses that can be treated as direct non-production costs has been used in order to score attribute $A_{c 3}$.

Table I: Demographic Data of Respondents

\begin{tabular}{|c|c|c|}
\hline Industry classification & $\mathbf{N}$ & $\mathbf{\%}$ \\
\hline Food and Beverages & 11 & 20.0 \\
\hline Wood and Paper Products & 6 & 25.9 \\
\hline Chemical Products & 14 & 16.4 \\
\hline Metal Industry & 9 & 18.2 \\
\hline Machinery and Equipment & 10 & $\underline{100.0}$ \\
\hline Other Manufacturing & 5 & $\%$ \\
\hline Total & $\underline{55}$ & 21.8 \\
\hline Position of respondent & $\mathrm{N}$ & 61.8 \\
\hline Chief accountant/Controller & 12 & 3.6 \\
\hline Financial manager & 34 & 12.7 \\
\hline General manager & 2 & $\underline{100.0}$ \\
\hline Other & $\mathbf{2}$ & \\
\hline Total & $\underline{55}$ & \\
\hline
\end{tabular}

Table II shows the companies' percentage proportions of separate cost items with reference to total cost. An analysis of the structure of production costs was also conducted. The results of this analysis are presented in Table III.

Table II: Cost Items as Percentage of Total Cost

\begin{tabular}{|c|c|c|}
\hline Cost item & Mean (\%) & Std. Deviation (\%) \\
\hline Materials & 47.15 & 20.43 \\
Direct labour & 12.01 & 12.20 \\
Manufacturing overhead & 17.98 & 12.78 \\
Other non manufacturing overhead & 23.00 & 11.21 \\
\hline Total cost & $\underline{100.00}$ & \\
\hline
\end{tabular}

Table III: Cost Items as Percentage of Production Cost

\begin{tabular}{|c|c|c|}
\hline Cost item & Mean (\%) & Std. Deviation (\%) \\
\hline Materials & 60.85 & 24.08 \\
Direct labour & 15.59 & 15.15 \\
Manufacturing overhead & 23.57 & 16.55 \\
\hline Total production cost & $\underline{\underline{100.00}}$ & \\
\hline
\end{tabular}




\section{Overhead Allocation}

The way overhead is allocated to products is one of the main reasons that may cause product costing distortions. Almost $60 \%$ of the companies in the sample use at least one of the directly volume driven allocation bases (i.e. direct labour hours, direct labour cost, machine hours). Burden rates calculated on the basis of material usage and production quantity are also commonly used. It is worth mentioning that $46 \%$ of the sample companies use both direct labour hours and machine hours to allocate indirect manufacturing costs. Overhead allocation information combined with cost structure information from the sample companies has been used in order to score attribute $A_{c 2}$.

\section{Using Cost Accounting Information For Decision Making}

Our results are very similar to views presented in earlier cost accounting research literature, arguing that the most important target of cost information is to support product pricing decisions. The majority of companies (percentages above 91\%) use cost accounting data (apart from pricing decisions) also for budget preparation and cost control. Finally, $76 \%$ of the sample companies use accounting data in order to evaluate inventories. The way the sample companies use cost accounting information for decision making has been used in order to score attribute $A_{c 4}$. Activity based costing implementation and perceived suitability

The analysis of the answers regarding $\mathrm{ABC}$ adoption in Greece revealed that $12.73 \%$ of the sample companies implement $\mathrm{ABC}$ ( 7 companies) and another $27.27 \%$ are partially implementing it (15 companies). It is however interesting to notice that $54.55 \%$ of the companies that do not use $\mathrm{ABC}$ (i.e., 18 companies out of 33) think that such a cost accounting system would be suitable for them. These findings are interesting for two reasons. The first is that a rate of adoption of around $10 \%$ is comparable to other contemporary studies for European countries. It has to be noted that a survey that has been undertaken in early 1990s in Greece had not revealed a single adopter (Ballas and Venieris, 1996). The second is that the interest towards ABC is rather in a growing phase in Greece in comparison to a more mature even declining phase that have been evidenced in UK (Innes et. al., 2000).

\section{Results Of The Model}

Two sets of results can be drawn; those that refer to the calculation of the values for each attribute and those that correspond to the positioning of the sample companies to the model matrix.

As for the first set, as every attribute can take values of either 1 or 0 (according to the hypothesis of attribute equivalence) the total score that a company can obtain either for cost accounting sophistication or production flexibility is from 0 to 5 . On the basis of these two scores a company can be positioned in one of the four quadrants of the model matrix. The theoretical result is that $\mathrm{ABC}$ would be more suitable for a company that is located in quadrants 2,3 or 4 . In Table IV we present the scores of the 10 attributes of the 55 companies per quadrant and in Table $\mathrm{V}$ the correlations among attributes.

It is interesting to find that there is a statistically significant relation at a statistical level of less that $5 \%$ (at 7 out of the 10 attributes) and of less that $10 \%$ (at 2 out of the 10 attributes) between the values of the attributes and the position of a company to a quadrant (Table IV). This means that all attributes, with the exception of $A_{c 3}$ in terms of statistical significance, are relevant and useful in positing a company to any of the matrix quadrants. This finding is further straightened by the lack of significant correlations among attributes (Table V). As our variables are dummy we use for the correlation calculation the contingency probability that is suitable for nominal variables. More specifically, as every attribute measures a different aspect of each variable we did not expect to find correlations among the attributes as discussed earlier. Moreover, if the different attributes were related, i.e. they were different views of only one aspect, then instead of scoring five different dimensions we would only score one. As expected there are no correlations among the attributes, except for two cases, the correlation between variables $\mathrm{A}_{\mathrm{c} 1}$ and $\mathrm{A}_{\mathrm{c} 3}$ (statistical significance 5\%) and the correlation between variables $\mathrm{A}_{\mathrm{f} 1}$ and $\mathrm{A}_{\mathrm{f} 2}$ (statistical significance $5 \%$ ). This finding enforces our original hypothesis that the dimensions are not interrelated and that each attribute tends to capture a different aspect regarding flexibility and cost structure characteristic. 
Table IV: Attribute Values per Quadrant

\begin{tabular}{|c|c|c|c|c|c|c|c|c|c|c|}
\hline & \multicolumn{2}{|c|}{$\mathbf{A}_{\mathrm{c} 1}$} & \multicolumn{2}{|c|}{$\mathbf{A}_{\mathrm{c} 2}$} & \multicolumn{2}{|c|}{$\mathbf{A}_{\mathrm{c} 3}$} & \multicolumn{2}{|c|}{$\mathbf{A}_{\mathbf{c 4}}$} & \multicolumn{2}{|c|}{$\mathbf{A}_{\mathrm{c} 5}$} \\
\hline & 0 & 1 & 0 & 1 & 0 & 1 & 0 & 1 & 0 & 1 \\
\hline Q1 & 10 & 6 & 14 & 2 & 12 & 4 & 12 & 4 & 10 & 6 \\
\hline Q2 & 16 & 8 & 16 & 8 & 18 & 6 & 17 & 7 & 17 & 7 \\
\hline Q3 & 5 & 0 & 1 & 4 & 2 & 3 & 0 & 5 & 1 & 4 \\
\hline Q4 & 3 & 7 & 2 & 8 & 7 & 3 & 4 & 6 & 1 & 9 \\
\hline Total & $\begin{array}{c}34 \\
(62 \%)\end{array}$ & $\begin{array}{c}21 \\
(38 \%)\end{array}$ & $\begin{array}{c}33 \\
(60 \%)\end{array}$ & $\begin{array}{c}22 \\
(40 \%)\end{array}$ & $\begin{array}{c}39 \\
(70 \%)\end{array}$ & $\begin{array}{c}16 \\
(29 \%)\end{array}$ & $\begin{array}{c}33 \\
(60 \%)\end{array}$ & $\begin{array}{c}22 \\
(40 \%)\end{array}$ & $\begin{array}{c}29 \\
(53 \%)\end{array}$ & $\begin{array}{c}26 \\
(47 \%)\end{array}$ \\
\hline $\begin{array}{c}\text { Pearson } X^{2} \\
\text { (Prob.) }\end{array}$ & \multicolumn{2}{|c|}{$\begin{array}{c}7.620 \\
(0.055)\end{array}$} & \multicolumn{2}{|c|}{$\begin{array}{l}15.486 \\
(0.001)\end{array}$} & \multicolumn{2}{|c|}{$\begin{array}{c}2.644 \\
(0.450)\end{array}$} & \multicolumn{2}{|c|}{$\begin{array}{l}11.840 \\
(0.008)\end{array}$} & \multicolumn{2}{|c|}{$\begin{array}{l}13.242 \\
(0.004)\end{array}$} \\
\hline $\begin{array}{c}\text { Contingency } \\
\text { coefficient } \\
\text { (Probability) }\end{array}$ & \multicolumn{2}{|c|}{$\begin{array}{c}.349 \\
(0.055)\end{array}$} & \multicolumn{2}{|c|}{$\begin{array}{c}.469 \\
(0.001)\end{array}$} & \multicolumn{2}{|c|}{$\begin{array}{c}.214 \\
(0.450)\end{array}$} & \multicolumn{2}{|c|}{$\begin{array}{c}.421 \\
(0.008)\end{array}$} & \multicolumn{2}{|c|}{$\begin{array}{c}.441 \\
(0.004)\end{array}$} \\
\hline
\end{tabular}

\begin{tabular}{|c|c|c|c|c|c|c|c|c|c|c|}
\hline & \multicolumn{2}{|c|}{$\mathbf{A}_{\mathrm{f} 1}$} & \multicolumn{2}{|c|}{$\mathbf{A}_{\mathrm{f} 2}$} & \multicolumn{2}{|c|}{$\mathbf{A}_{\mathrm{f3}}$} & \multicolumn{2}{|c|}{$\mathbf{A}_{\mathrm{f} 4}$} & \multicolumn{2}{|c|}{$\mathbf{A}_{\mathrm{f5}}$} \\
\hline & 0 & 1 & 0 & 1 & 0 & 1 & 0 & 1 & 0 & 1 \\
\hline Q1 & 9 & 7 & 11 & 5 & 13 & 3 & 12 & 4 & 10 & 6 \\
\hline Q2 & 3 & 21 & 9 & 15 & 11 & 13 & 8 & 16 & 6 & 18 \\
\hline Q3 & 2 & 3 & 3 & 2 & 5 & 0 & 4 & 1 & 4 & 1 \\
\hline Q4 & 1 & 9 & 2 & 8 & 5 & 5 & 4 & 6 & 1 & 9 \\
\hline Total & $\begin{array}{c}15 \\
(27 \%)\end{array}$ & $\begin{array}{c}40 \\
(73 \%)\end{array}$ & $\begin{array}{c}25 \\
(45 \%)\end{array}$ & $\begin{array}{c}30 \\
(55 \%)\end{array}$ & $\begin{array}{c}34 \\
(62 \%)\end{array}$ & $\begin{array}{c}21 \\
(38 \%)\end{array}$ & $\begin{array}{c}28 \\
(51 \%)\end{array}$ & $\begin{array}{c}27 \\
(49 \%)\end{array}$ & $\begin{array}{c}21 \\
(38 \%)\end{array}$ & $\begin{array}{c}34 \\
(62 \%)\end{array}$ \\
\hline $\begin{array}{c}\text { Pearson } X^{2} \\
\text { (Probability) }\end{array}$ & \multicolumn{2}{|c|}{$\begin{array}{l}11.327 \\
(0.010)\end{array}$} & \multicolumn{2}{|c|}{$\begin{array}{c}7.155 \\
(0.067)\end{array}$} & \multicolumn{2}{|c|}{$\begin{array}{c}8.838 \\
(0.032)\end{array}$} & \multicolumn{2}{|c|}{$\begin{array}{c}8.851 \\
(0.031)\end{array}$} & \multicolumn{2}{|c|}{$\begin{array}{l}12.845 \\
(0.005)\end{array}$} \\
\hline $\begin{array}{l}\text { Contingency } \\
\text { coefficient } \\
\text { (Probability) }\end{array}$ & \multicolumn{2}{|c|}{$\begin{array}{c}.413 \\
(0.010)\end{array}$} & \multicolumn{2}{|c|}{$\begin{array}{c}.339 \\
(0.067)\end{array}$} & \multicolumn{2}{|c|}{$\begin{array}{c}.372 \\
(0.032)\end{array}$} & \multicolumn{2}{|c|}{$\begin{array}{c}.372 \\
(0.031)\end{array}$} & \multicolumn{2}{|c|}{$\begin{array}{c}.435 \\
(0.005)\end{array}$} \\
\hline
\end{tabular}

The plotting of the companies in the four quadrants of the model matrix according to their scores is presented in Figure 2.

Table V: Correlations of Attributes' Values

\begin{tabular}{|c|c|c|c|c|c|c|c|c|c|c|}
\hline $\mathbf{A}_{\mathrm{c} 1}$ & $\begin{array}{c}A_{c 1} \\
1.000\end{array}$ & $\begin{array}{c}\mathbf{A}_{\mathbf{c} 2} \\
.180 \\
(.174)\end{array}$ & $\begin{array}{c}\mathbf{A}_{\mathbf{c 3}} \\
\mathbf{. 3 2 1} * \\
(.012)\end{array}$ & $\begin{array}{c}\mathbf{A}_{\mathbf{c 4}} \\
.106 \\
(.428)\end{array}$ & $\begin{array}{c}\mathbf{A}_{\mathbf{c 5}} \\
.080 \\
(.551)\end{array}$ & $\begin{array}{c}\mathbf{A}_{\mathbf{f 1}} \\
0.61 \\
(.650)\end{array}$ & $\begin{array}{c}\mathbf{A}_{\mathbf{f} 2} \\
0.41 \\
(.761)\end{array}$ & $\begin{array}{c}\mathbf{A}_{\mathbf{f 3}} \\
.078 \\
(.561)\end{array}$ & $\begin{array}{c}\mathbf{A}_{\mathbf{f 4}} \\
.023 \\
(.864)\end{array}$ & $\begin{array}{c}\mathbf{A}_{\mathbf{f 5}} \\
.154 \\
(.249)\end{array}$ \\
\hline $\mathbf{A}_{\mathrm{c} 2}$ & & 1.000 & $\begin{array}{c}.049 \\
(.716)\end{array}$ & $\begin{array}{c}.091 \\
(.500)\end{array}$ & $\begin{array}{l}.190 \\
(.152)\end{array}$ & $\begin{array}{c}.083 \\
(.537)\end{array}$ & $\begin{array}{c}.074 \\
(.580)\end{array}$ & $\begin{array}{l}.121 \\
(.365)\end{array}$ & $\begin{array}{c}.231 \\
(.078)\end{array}$ & $\begin{array}{l}.106 \\
(.428)\end{array}$ \\
\hline $\mathbf{A}_{\mathrm{c} 3}$ & & & 1.000 & $\begin{array}{c}.049 \\
(.716)\end{array}$ & $\begin{array}{c}.045 \\
(.737)\end{array}$ & $\begin{array}{c}.057 \\
(.671)\end{array}$ & $\begin{array}{c}.058 \\
(.665)\end{array}$ & $\begin{array}{c}.154 \\
(.248)\end{array}$ & $\begin{array}{c}.068 \\
(.612)\end{array}$ & $\begin{array}{l}.0009 \\
(.947)\end{array}$ \\
\hline $\mathbf{A}_{\mathrm{c} 4}$ & & & & 1.000 & $\begin{array}{c}.104 \\
(.440)\end{array}$ & $\begin{array}{c}.083 \\
(.537)\end{array}$ & $\begin{array}{c}.074 \\
(.580)\end{array}$ & $\begin{array}{c}.046 \\
(.734)\end{array}$ & $\begin{array}{c}.132 \\
(.322)\end{array}$ & $\begin{array}{c}.031 \\
(.821)\end{array}$ \\
\hline$A_{c 5}$ & & & & & 1.000 & $\begin{array}{c}.245 \\
(.061)\end{array}$ & $\begin{array}{c}.202 \\
(.126)\end{array}$ & $\begin{array}{l}.069 \\
(.606)\end{array}$ & $\begin{array}{c}.017 \\
(.898)\end{array}$ & $\begin{array}{c}.005 \\
(.968)\end{array}$ \\
\hline $\mathbf{A}_{\mathrm{f} 1}$ & & & & & & 1.000 & $\begin{array}{l}.324 * \\
(.011)\end{array}$ & $\begin{array}{c}.023 \\
(.865)\end{array}$ & $\begin{array}{c}.132 \\
(.322)\end{array}$ & $\begin{array}{l}.106 \\
(.428)\end{array}$ \\
\hline$A_{f 2}$ & & & & & & & 1.000 & $\begin{array}{l}.115 \\
(.389)\end{array}$ & $\begin{array}{c}.125 \\
(.349)\end{array}$ & $\begin{array}{c}.041 \\
(.761)\end{array}$ \\
\hline $\mathbf{A}_{\mathbf{f 3}}$ & & & & & & & & 1.000 & $\begin{array}{c}.052 \\
(.701)\end{array}$ & $\begin{array}{c}.075 \\
(.575)\end{array}$ \\
\hline $\mathbf{A}_{\mathrm{f4}}$ & & & & & & & & & 1.000 & $\begin{array}{c}.098 \\
(.467)\end{array}$ \\
\hline $\mathbf{A}_{\mathrm{f5}}$ & & & & & & & & & & 1.000 \\
\hline
\end{tabular}

Contingency coefficient (probability)

*Significant at 5\% significance level

$\mathrm{N}=55$ 
Figure 2: Plotting of the Model Results

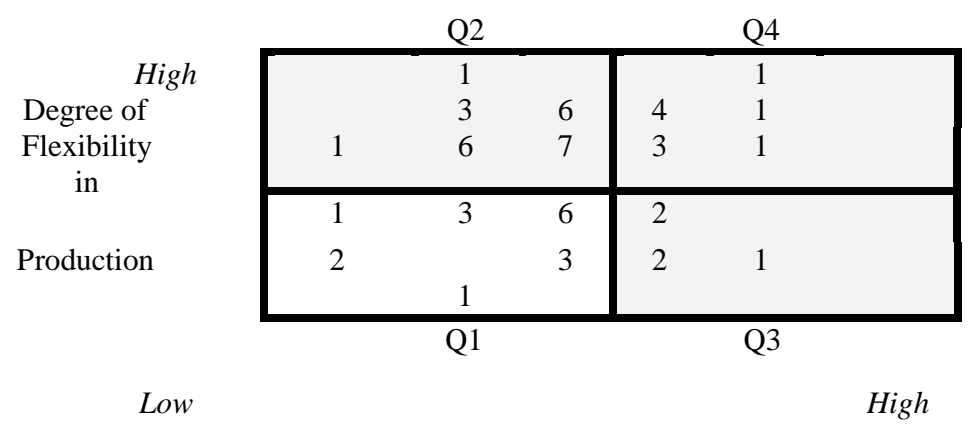

Suitability of more sophisticated cost accounting system

As for the second set of results, Table VI shows the total concentration of companies per quadrant. The figures in the matrix correspond to the number of companies that are assigned by the model to the coordinates of the matrix. From Table VI we can draw the conclusion that not all companies in the sample, according to model results, are in need of a more sophisticated cost system as $29.1 \%$ of them lay in quadrant 1 . However, a more sophisticated cost accounting system is needed for the 39 out of the 55 companies (70.9\%). More specifically, the majority of these companies, 24 out of the 39 , lie in quadrant 2 . In other words they need a more sophisticated cost accounting system due to their increased flexibility. Only 5 out of 39 companies lie in quadrant 3 , where the driving force for $\mathrm{ABC}$ adoption is not the flexibility dimension but rather cost management aspects. Finally, the model revealed that 10 companies are positioned in quadrant 4 , where both cost accounting sophistication needs and increased flexibility advocated in favour of $\mathrm{ABC}$ adoption.

Table VI: Results of the Model

\begin{tabular}{|c|c|c|}
\hline Quadrant & Number of companies & \% of total \\
\hline Quadrant 1 & 16 & 29.1 \\
\hline Quadrant 2 & 24 & 43.6 \\
\hline Quadrant 3 & 5 & 9.1 \\
\hline Quadrant 4 & 10 & 18.2 \\
\hline Total & $\underline{\underline{55}}$ & $\underline{\underline{100.0}}$ \\
\hline
\end{tabular}

However, this theoretical result should be empirically tested for its validity. The real reference point against which the theoretical results could be tested was the opinion of the managers of the companies questioned. In the questionnaire, the managers, as experts having a global view of their firm, were asked to identify whether an ABC system would be appropriate for their companies. As explained next, the statistical significance test was based on the comparison between the model's theoretical results and the experts' opinions. If the null hypothesis (i.e. that the model's theoretical results and the experts' opinions are independent) is rejected, then one can conclude that the decision model matrix developed can be safely used in the decision making process concerning ABC adoption and implementation.

The results of the statistical significance test on the comparison between the theoretical categorization made by the decision model matrix and the experts' opinion are shown in Table VII. This test aims at revealing whether there is convergence between the two constructs. The basic assumption behind this comparison is that the managers' responses are an accurate and unbiased judgement for $\mathrm{ABC}$ suitability.

The results in Table VII are based on the Chi -square test and show that the hypothesis of independence between the two constructs is rejected at the 5\% significance level. Thus, the results of the test and managers 
perceptions are related. This means that the model can successfully assess ABC's suitability for a company at $5 \%$ significance level.

Table VII: Experts' Opinion vs. Model Results on ABC

\begin{tabular}{|c|c|c|c|c|}
\hline & \multicolumn{2}{|c|}{ Suitability of ABC } & Chi- square Value & Significance (2 sided) \\
\hline & Yes & No & & \\
\hline Model predicts & 39 & 16 & & 0.010 \\
\hline Experts judge & 35 & 20 & $6.661^{\mathrm{a}}$ & \\
\hline
\end{tabular}

${ }^{\mathrm{a}} 0$ cells $(0 \%)$ have expected count less than 5 and the minimum expected count is 5.82 .

\section{CONCLUSIONS}

In this paper we have developed a decision matrix model which, by combining several attributes that, according to theory and previous empirical findings, characterize sophisticated cost accounting systems and flexibility in production, indicates whether $\mathrm{ABC}$ implementation is recommended. We identified ten attributes, five per dimension, that are not related to each other in order to capture the different aspects of cost characteristics and flexibility that can be itemized within a company. The model is built on objective and measurable parameters. Thus, it is an easy to handle and flexible tool in order to assist managers upon deciding on the adoption of a resource consuming and difficult to realise project like $\mathrm{ABC}$.

Our theoretical model was empirically tested for its validity in 55 Greek manufacturing companies and it successfully identified the companies for which the adoption and implementation of an $\mathrm{ABC}$ system is suitable and recommendable. The results of the model were as good as those of expert managers. Furthermore, the results of our testing verified the qualities of independence and significance of the different attributes identified. Another interesting conclusion of its empirical testing that contributes to the $\mathrm{ABC}$ paradox literature by explaining why $\mathrm{ABC}$ has not replaced traditional cost accounting systems as expected, is that some companies do not seem to need it. Twenty-nine percent of our sample companies belong, according to the model results, to this category because they have low flexibility and low cost accounting needs. On the other hand, the model results revealed that production flexibility is a significant factor driving companies towards $\mathrm{ABC}$ adoption as 34 out of the 39 of the sample companies that were $\mathrm{ABC}$ recommended possessed increased levels of this dimension.

The empirical testing of the model used actual data that were gathered via questionnaires in 1999. The analysis of these data give us no reasons to believe that Greek manufacturing companies deviate considerably as far as their cost accounting aspects and production flexibility profile are concerned from their European counterparts. Moreover, empirical evidence regarding cost structure (Lukka and Grandlund, 1996) and application of advanced manufacturing technologies (Lukka and Grandlund, 1996; Abdel - Kader and Duglale, 1998) supports this view. Thus as the model is not constrained to Greek idiosyncrasy, it could have a broader use.

\section{APPENDIX: ATTRIBUTES' SCORING CALCULATIONS}

Attribute $A_{c 1}$ takes the value of 1 for companies whose indirect cost contribution to production cost $\left(X_{1}\right)$ is higher than the average percentage of indirect cost to production cost of the sample firms $\left(\bar{X}_{1}\right)$ and 0 otherwise.

$A_{c 1}=\left\{\begin{array}{l}1, \text { when } X_{1 j} \geq \overline{X_{1}} \text { where } \overline{X_{1}}=\frac{\sum_{j=1}^{55} X_{1 j}}{55} \\ 0, \text { when } X_{1 j}<\overline{X_{1}}\end{array}\right.$ 
Attribute $A_{c 2}$ takes the value of 1 for companies whose percentage contribution of direct labour to total production $\operatorname{cost}\left(X_{2}\right)$ is less than the average of the sample firms $\left(\bar{X}_{2}\right)$ and they use direct labour related allocation bases (direct labour hours, DLH or direct labour cost, DLC) and 0 otherwise.

$A_{c 2}=\left\{\begin{array}{l}1, \text { when } X_{2 j} \leq \overline{X_{2}} \text { and }(\mathrm{DLH}=\text { true or DLC }=\text { true }) \text { where } \overline{X_{2}}=\frac{\sum_{j=1}^{55} X_{2 j}}{55} \text { Attribute } A_{c 3} \text { takes the value of } \\ 0, \text { all other combinations }\end{array}\right.$

1 for companies whose the percentage of selling and marketing expenses that can be treated as direct product costs $\left(X_{3}\right)$ are higher than the average corresponding percentage of the sample firms $\left(\bar{X}_{3}\right)$ and 0 otherwise.

$A_{c 3}=\left\{\begin{array}{l}1, \text { when } X_{3 j} \geq \overline{X_{3}} \text { where } \overline{X_{3}}=\frac{\sum_{j=1}^{55} X_{3 j}}{55} \\ 0, \text { when } X_{3 j}<\overline{X_{3}}\end{array}\right.$

Attribute $A_{c 4}$ takes the value of 1 for companies that want to have cost data that do not relate on one hand to traditional cost bearers but want to have cost data relevant for decision making related aspects like pricing, cost control and product mix and 0 otherwise.

Attribute $A_{c 5}$ takes the value of 1 for companies whose all the other cost items, except the cost of goods sold $\left(X_{4}\right)$, contribute to their total cost to a percentage that is above the average of the sample firms $\left(\bar{X}_{4}\right)$ and 0 otherwise.

$A_{c 5}=\left\{\begin{array}{l}1, \text { when } X_{4 j} \geq \overline{X_{4}} \text { where } \overline{X_{4}}=\frac{\sum_{j=1}^{55} X_{4 j}}{55} \\ O, \text { when } X_{4 j}<\overline{X_{4}}\end{array}\right.$

Attribute $A_{f I}$ takes the value of 1 for companies that can produce a high variety of products through the same machinery facilities and 0 otherwise.

Attribute $A_{f 2}$ takes the value of 1 for companies that their capability in changing product characteristics by using the same machinery facilities is high (according to the questionnaire definitions) and 0 otherwise.

Attribute $A_{f 3}$ takes the value of 1 for companies that perform frequent set-ups for which there is no waste of time or there is a small delay (according to the questionnaire definitions) during the changes and 0 otherwise. 
Attribute $A_{f t}$ takes the value of 1 for companies that both produce products in batch sizes that are approximately equivalent to delivery requirements and the set-up convenience and related costs do not influence their batch size and 0 otherwise.

Attribute $A_{f 5}$ takes the value of 1 for companies that use automated means for the movement of at least two of the following: raw materials, work-in-process and finished goods and 0 otherwise.

\section{REFERENCES}

1. Abdel - Kadar, M. and Duglade, D. (1998) Investment in advanced manufacturing technology: a study of practice in large U.K. companies, Management Accounting Research, 9, pp. 261-284.

2. Abernethy, M. and Lillis A. (1995) The impact of Manufacturing Flexibility on Management Control System Design, Accounting, Organizations and Society, 20, 4, pp. 241-258.

3. Anderson, S. W. and Young M. (1999) The impact of contextual and process factors on the evaluation of activity-based costing systems, Accounting, Organizations and Society, 24, pp. 525-559.

4. Armitage, H. M. and Nicholson, R. (1993) Activity based costing: a survey of Canadian practice, Issue paper No. 3, Society of Management Accountants of Canada.

5. Ask, U., Ax, C. and Jonsson, S. (1996) Cost management in Sweden: from modern to post-modern, in Bhimani, A. (ed.) Management Accounting: European Perspectives, Oxford, Oxford University Press, pp. 199-217.

6. Avlonitis, G. and Parkinson, St. (1986) The Adoption of Flexible Manufacturing Systems in British and German Companies, Industrial Marketing Management, 15, pp. 97-108.

7. Ballas, A. and Venieris, G. (1996) A survey of Management Accounting Practice in Greek Firms, in Bhimani, A. (ed.) Management Accounting: European Perspectives, Oxford, Oxford University Press, pp. 123-139

8. Banerjee, J. and Kane, W. (1996) Report on CIMA / JBA survey, Management Accounting, October, pp. 30-37.

9. Barbato, M. B., Collini and Quagli, P. (1996) Management accounting in Italy, in Bhimani, A. (ed.) Management Accounting: European Perspectives, Oxford, Oxford University Press, pp. 140-163.

10. Beach, R., Muhlemann A. P., Price D. H. R., Paterson A. and Sharp J.A. (2000) A review of manufacturing flexibility, European Journal of Operational Research, 122, pp. 41- 57.

11. Bjørnenak, T and Mitchell F. (2002) The development of activity-based costing journal literature, 19872000, The European Accounting Review, 11:3, pp. 481-508.

12. Bjørnenak, T. (1997) Diffusion and Accounting: The case of ABC in Norway, Management Accounting Research, Vol. 8, No. 1, pp 3-17.

13. Bromwitch, M. and C. Hong (1999) Activity Based Costing and Incremental Costs, Management Accounting Research, 10, pp. 39-60.

14. Browne, J., Dubois D., Rathmill K., Sethi S. P. and Stecke K. E. (1984) Classification of flexible manufacturing systems, The FMS Magazine, April, pp. 114-117.

15. Bruggeman, W., Slagmulder, R. and Waeytens, D. (1996) Management accounting changes: the Belgian experience, in Bhimani, A. (ed.) Management Accounting: European Perspectives, Oxford, Oxford University Press, pp. 1-30.

16. Chen, F. (1996) Activity-based approach to justification of advanced factory management systems, Industrial Management \& Data Systems, 96/2, pp. 17-24.

17. Chenhall, H. R. and Langfield-Smith, K. (1998) 'Adoption and Benefits of Management Accounting Practices: An Australian Study, Management Accounting Research, Vol. 9, pp. 1-19.

18. Clarke, P.J., Hill, N.T. and Stevens, K. (1999), Activity based costing in Ireland: barriers to, and opportunities, for change, Critical Perspectives on Accounting, Vol. 10, pp. 443-468.

19. Cobb, I., Innes, J. and Mitchell, F. (1992) Activity-Based Costing_Problems in Practice, London, CIMA.

20. Cohen, J. R. and Paquett, L. (1991) Management accounting practices: perceptions of controllers, Journal of Cost Management for the manufacturing industry, Fall, 5, pp. 73-83.

21. Cooper, R. and Kaplan, R. S. (1991) Profit priorities from activity-based costing, Harvard Business Review, May-June, pp. 130-135. 
22. Cooper, R. and Kaplan, R. S. (1992) Activity-based systems: measuring the costs of resource usage, Accounting Horizons, September, pp. 1-13.

23. Cooper, R. and Kaplan, R. S. (1998) Cost and Effect, Boston, Harvard Business School Press.

24. Cooper, R. (1988a) Cost management concepts and principles: the rise of activity based costing - part one what is an activity-based cost system, Journal of Cost Management, Summer, pp. 45-54.

25. Cooper, R. (1988b) The rise of activity-based costing - part two: when do I need an activity-based costing system?, Journal of Cost Management, Fall, pp. 41-48.

26. D' Souza, D. E and Williams F. P. (2000) Toward a taxonomy of manufacturing flexibility dimensions, Journal of Operations Management, 18, pp. 577-593.

27. Drury, C. and Tayles M. (1994) Product costing in U.K manufacturing organizations, European Accounting Review, 3 (3), pp. 443-469.

28. Evans, H. and Ashworth, G. (1996) Survey conclusions: wakeup to the competition, Management Accounting (U.K), May, pp. 16-18.

29. Foster, G. and Horngren, Ch. (1988) Flexible Manufacturing Systems: Cost Management and Cost Accounting Implications Journal of Cost Management, Fall, pp. 16-24.

30. Foster, G. and Swenson, D. G. (1997) Measuring the success of activity-based cost management and its determinants, Management Accounting Research, 9, pp. 109-142.

31. Friedman, A. L. and Lyne, S. R. (1999) Success and Failure of Activity-based Techniques: A Long Term Perspective, London, Chartered Institute of Management Accountants.

32. Gerwin, D. (1993) Manufacturing flexibility: A strategic perspective, Management Science, 39 (4), pp. 395 -410 .

33. Groot, T.L.C.M. (1999), Activity based Costing in U.S. and Dutch food companies, Advances in Management Accounting, Vol. 7, pp. 47-63.

34. Gosselin, M. (1997) The Effect of Strategy and Organizational Structure on the Adoption and Implementation of Activity-Based Costing, Accounting, Organizations and Society, Vol. 22, No. 2, pp. $105-122$.

35. Green, F. B and Amenkhienan, F. E. (1992) Accounting innovations: a cross - sectional survey of manufacturing firms, Journal of Cost Management, 6, pp. 58-64.

36. Gupta, Y. P and Somers T. M. (1996) Business strategy, manufacturing flexibility, and organizational performance relationships: a path analysis approach, Production and Operations Management, 5 (3), pp. 204-233.

37. Gupta, Y.P. and Goyal S. (1989) Flexibility of manufacturing systems: Concepts and measurements, European Journal of Operational Research, 43, pp. 119-135.

38. Gupta, Y.P. and Somers T. M. (1992) The measurement of manufacturing flexibility, European Journal of Operational Research, 60 (2), pp. 166-182.

39. Innes, J. and Mitchell, F. (1991) Activity based costing a survey of CIMA members, Management Accounting, October, pp. 28-30.

40. Innes, J. and Mitchell, F. (1995) A survey of activity based costing in the U.K's largest companies, Management Accounting Research, June, pp. 137-153.

41. Innes, J., Mitchell F. and Sinclair D. (2000) Activity-based costing in the U.K.'s largest companies: a comparison of 1994 and 1999 survey results, Management Accounting Research, 11, pp. 349-362.

42. Israelsen, P., Anderson, M., Rohde, C. and Sorensen, P. E. (1996) Management accounting in Denmark: theory and practice, in Bhimani, A. (ed.) Management Accounting: European Perspectives, Oxford, Oxford University Press, pp. 31-53.

43. Johnson, H. T. and Kaplan, R. (1987) Relevance Lost: The Rise and Fall of Management Accounting, Boston: Harvard Business School Press.

44. Johnston, R., Brignall S. and Fitzgerald L. (2002) The involvement of management accountants in operational process change: Results from a field research, International Journal of Operations and Production Management, Vol.20, No 12, pp.1325-1338.

45. Kaplan S. R. (1993) Measuring Manufacturing Performance: A New Challenge for Managerial Accounting Research, The Accounting Review, Vol. LVIII, No. 4, pp. 686-705.

46. Kaplan, R. S. (1992) In defence of activity-based cost management, Management Accounting (US), Nov., pp. 58-63. 
47. Kaplan, S. R. (1983) Measuring Manufacturing Performance: A New Challenge for Managerial Accounting Research, The Accounting Review, Vol. LVIII, No 4, October, pp. 686-705.

48. Koltai, T., Lozano S., Guerrero F. and Onieva L. (2000) A flexible costing system for flexible manufacturing systems using activity based costing, International Journal of Production Research, Vol. 38, No7, pp. 1615-1630.

49. Lukka, K. and Granlund, M. (1996) Cost Accounting in Finland: Current Practice and Trends of Development, The European Accounting Review, Vol. 5/1, pp. 1-28.

50. Malmi, T. (1997) Towards explaining activity-based costing failure: accounting and control, in a decentralised organisation, Management Accounting Research, 8, pp. 459-480.

51. Malmi, T. (1999) Activity- based costing diffusion across organizations: an explanatory empirical analysis of Finnish firms, Accounting Organizations and Society, 24, pp. 649-672.

52. McGowan, A. S. and Klammer, T. P. (1997) Satisfaction with activity-based costing cost management implementation, Management Accounting Research, 9, pp. 217-237.

53. Nicholls, B. (1992) ABC in the U.K - a status report, Management Accounting, May, pp 22-23.

54. Saez-Torrecilla, A., Fernandez - Fernandez, A., Texeira - Quiros, J. and Vaquera-Mosquero, M., (1996) Management accounting in Spain: trends in thought and practice, in Bhimani, A. (ed.) Management Accounting: European Perspectives, Oxford, Oxford University Press, p.p. 180-190.

55. Scherrer, G. (1996) Management Accounting: a German perspective, in Bhimani, A. (ed.) Management Accounting: European Perspectives, Oxford, Oxford University Press, p.p. 100-122.

56. Sethi, A.K. and Sethi S. P. (1990) Flexibility in manufacturing: A survey International Journal of Flexible Manufacturing Systems, 2, pp. 289-328.

57. Shields, M. (1995) An empirical analysis of firms' implementation experiences with activity-based costing, Journal of Management Accounting Research, 9, pp. 148-166.

58. Shim, E. and Sudit, E. (1995) How manufactures price products, Management Accounting (U.K), February, pp. 37-39.

59. Suarez, F. F., Cusumano, M. A. and Fine, C. H. (1995) An Empirical Study of Flexibility in Manufacturing, Sloan Management Review, Fall, pp. 25-32.

60. Upton, D.M. (1995) Flexibility as process mobility: the management of plant capabilities for quick response manufacturing, Journal of Operations Management, 13, (3-4) , pp. 205-224.

61. Vokurka, R. J. and O’Leary-Kelly S. W. (2000) A review of empirical research on manufacturing flexibility, Journal of Operations Management, 18, pp. 485-501 